\title{
State of Chromium Atoms, Clustering, and Interatomic Interactions in Doped Lanthanum Gallate $\mathrm{La}(\mathrm{Sr}) \mathrm{Ga}(\mathrm{Cr}, \mathrm{Mg}) \mathrm{O}_{3-\delta}$
}

\author{
N.V. Chezhina and D.A. Korolev* \\ Department of General and Inorganic chemistry, St. Petersburg State University, Universitetskii pr. 26, St. Petersburg, \\ 198504, Russia
}

\begin{abstract}
The fractions of various clusters and single chromium atoms were calculated for a series of $\mathrm{La}_{1-0.2 x} \mathrm{Sr}_{0.2 x} \mathrm{Cr}_{x} \mathrm{Ga}_{1-}$ ${ }_{1.2 x} \mathrm{Mg}_{0.2 x} \mathrm{O}_{3-\delta}$ solid solutions $(0.01<x<0.10)$ within the context of diluted solution and Heizenberg-Dirack-van Vleck models. An essential influence of both the nature and concentration of heterovalent diamagnetic substituent on the quantitative and qualitative composition of chromium atom clusters was shown. These clusters include also strontium, magnesium atoms, and oxygen vacancies.
\end{abstract}

Keywords: Doped lanthanum gallate, magnetic susceptibility, electronic structure of solids, electron-ionic conductivity.

\section{INTRODUCTION}

Simultaneous doping of lanthanum gallate with alkalineearth elements and magnesium makes it possible to obtain a wide spectrum of compounds with ionic conductivity. Introduction of transition elements into the gallium sites, on the whole, contributes to the appearance of electronic component of conductivity. An active search for the compositions providing for maximal ionic and (or) electronic conductivity is going on from 1994, when for the first time the ionic conductivity was found in lanthanum gallate doped with strontium, calcium, barium, and magnesium [1].

This is accounted for by practical importance of the materials based on doped lanthanum gallates in the production of solid oxide fuel cells (SOFC).

The tolerance of perovskite structure of lanthanum gallate to various substitutions allows a wide spectrum of compositions to be obtained, which have various qualitative and quantitative composition and, consequently, various properties. Doped gallates are used as a rule as electrolytes in SOFC [2-7]. In such a case the cathodes must have both electronic and ionic conductivity and the electrolytes purely ionic. Gallate doped with strontium and magnesium, as an electrolyte, is now a popular subject for SOFC operating in the middle temperature region $\left(600-800^{\circ} \mathrm{C}\right)$.

A large number of works is devoted to the study of the structure of lanthanum gallate and its derivatives [8-22]. The data on structural analysis are ambiguous, which is substantially determined not only by the synthetic procedure but also by the quality of starting reagents. The study [9] is particularly remarkable, since the structure of $\mathrm{La}_{1-x} \mathrm{Sr}_{x} \mathrm{Ga}_{1}$. ${ }_{y} \mathrm{Mg}_{y} \mathrm{O}_{3-\delta}$ is determined as a function of inserted $\mathrm{Sr}$ and $\mathrm{Mg}$ : orthorhombic at $x+y<0.25$; orthorhombic and rhombohedral

*Address correspondence to this author at the Department of General and Inorganic Chemistry, St Petersburg State University, Dmitry Korolev St. Petersburg State University, Chemical Faculty, Universitetskii pr. 26, St. Petersburg, 198504, Russia; Tel: +7(812)4284096; Fax: +7(812)4286939: E-mail: chemdim@mail.ru at $0.25<x+y<0.30$; at $x+y>0.30$, if $x$ or $y \geq 20$ - cubic. By various data the structural phase transitions in pure and doped lanthanum gallate can occur in a wide range of temperatures [16, 18, 20-22].

The chice of strontium and magnesium as heterovalent substituents is not casual, though the greater stability of $\mathrm{Sr}$ and $\mathrm{Mg}$ doped gallate compared to $\mathrm{Ba}$ and $\mathrm{Ca}$ containing analogs was found experimentally [1]. The thermodynamic examination shows a lesser endothermic effect of the solid solution formation on introduction of $\mathrm{Sr}(138 \pm 12 \mathrm{~kJ} / \mathrm{mol}$ for $\mathrm{La}_{1-x} \mathrm{Sr}_{x} \mathrm{Ga}_{1-y} \mathrm{Mg}_{y} \mathrm{O}_{3-\delta}$ and $166 \pm 12 \mathrm{~kJ} / \mathrm{mol}$ for $\mathrm{La}_{1-x} \mathrm{Ba}_{x} \mathrm{Ga}_{1-}$ $\left.{ }_{y} \mathrm{Mg}_{y} \mathrm{O}_{3-\delta} ; x>0, y \leq 0.2\right)$ or magnesium $(275 \pm 37 \mathrm{~kJ} / \mathrm{mol}$ for $\left.\mathrm{LaGa}_{1-y} \mathrm{Mg}_{y} \mathrm{O}_{3-\delta} ; y \leq 0.2\right)$ [23]. This suggests that $\mathrm{Sr}$ and $\mathrm{Mg}$ are the most sutable doping elements in lanthanum gallate from the elements of the II group of Periodic table.

A number of works on computer simulation are devoted to the stability of doped lanthanum gallates and their electron structure [24-26]. The data of Khan using the statistic lattice simulation method [24] are in good agreement with endothermic character of experimental values in [23].

It is interesting to note that by the data of computer simulation the formation of oxygen vacancies upon heterovalent substitution of lanthanum gallate results in its destabilization, whereas doping zirconium oxide with yttrium contributes to the stabilization of fluorite structure [23]. In $\mathrm{Sr}$ and $\mathrm{Mg}$ doped gallate the binding energy of "bivalent cation - vacancy" for a $\mathrm{Mg}_{\mathrm{Ga}}{ }^{\prime} \mid V_{\mathrm{O}}$ couple was found to be $-0.90 \mathrm{~kJ} / \mathrm{mol}$, for a $\mathrm{Sr}_{\mathrm{La}}{ }^{\prime} \mid V_{\mathrm{O}}$ couple $--0.01 \mathrm{~kJ} / \mathrm{mol}$ [25], which can be a promising factor favoring an increase in the oxygen conductivity on introduction of strontium. The data of calculations [24] are in agreement with experimental transport numbers in gallates doped with strontium and magnesium, where a decrease in the oxygen transport numbers is noted for the systems containing only strontium compared to magnesium containing solutions $\left(t_{O} 0.98\right.$ for $\mathrm{La}_{0.9} \mathrm{Sr}_{0.1} \mathrm{GaO}_{3-\delta}$ and 0.92 for $\mathrm{LaGa}_{0.85} \mathrm{Mg}_{0.15} \mathrm{O}_{3-\delta}$ at $\left.1073 \mathrm{~K}\right)$ [27].

An attention must be paid to a serious problem upon doping lanthanum gallate with alkaline-earth metals and magne- 
sium only - the obtained samples are not single phase. Again in this case much depends on the conditions and methods of the synthesis and also on the very precursors. Aside from the phase of gallate many researchers found admixed phases, such as $\mathrm{LaSrGaO}_{4}$ and $\mathrm{LaSrGa}_{3} \mathrm{O}_{7}$ [8-11, 27-38], in all cases where the solubility of strontium is exceeded or close to the limit. By the data of [1] the limit of strontium solubility in $\mathrm{LaGaO}_{3}$ is 10 at \%. It is interesting to note that introduction of magnesium only up to 20 at $\%$ does not result in admixture phases [28]. An excess of magnesium results in the isolation of $\mathrm{La}_{4} \mathrm{Ga}_{2} \mathrm{O}_{9}, \mathrm{LaSrGaO}_{4}$, and $\mathrm{LaSrGa}_{3} \mathrm{O}_{7}$. As a rule the quantity of admixture phases is small and attains no more than $5 \%$. The reason for their appearance is the instability of the structure of doped gallate, which, as has been shown above, can be accounted for by thermodynamics. That means that in general from energetic point of view the emergence of oxygen vacancies is unfavorable. The admixture phases being insulating to a large extent result in a decrease in the conductivity and in a decrease in the life time of a material. In some cases the admixture compounds were not detected [39].

At the same time in some works the effects of stabilization of the structure of lanthanum gallate doped with $\mathrm{Sr}$ and (or) $\mathrm{Mg}$ were found upon introduction of transition element ions $[40,41]$.

In the studies of conductivity much attention is being given to lanthanum gallates doped aside from strontium and magnesium with transition elements [4, 27, 34, 35, 42-54]. In this case we deal with electron-ionic conductors, which are interesting not only from applied point of view, but also from the point of view of fundamental studies. The main intriguing problem in this case is the separation of electronic and ionic components of conductivity, which is sometimes a very complicated problem.

For elucidating the qualitative and quantitative regularities in the systems in question the most important seems to be the knowledge of their electron structure. This includes not only the valence and spin states of the atoms, but also their mutual influence and the special features of interatomic interactions. The changes in the type of conductivity on varying the qualitative or quantitative composition of conductors is directly associated with interatomic interactions and atom states in their structure. As for now the question about the electron structure of doped lanthanum gallate remains open, being partially solved on using the quantum chemistry calculations.

There is an opinion that introduction of strontium together with a transition metal into $\mathrm{LaGaO}_{3}$ results in a partial transition of trivalent element into a higher valence state, usually $+4[27,43-44,55]$ and sometimes even +5 [45]. The conclusion about the change in the valence state of a transition element is made from indirect data: a decrease in the volume of the unit cell (since cations with greater charge have a smaller ionic radius [56]) [44], or an increase in the activation energy of ionic conductivity (compared to $\left.\mathrm{La}(\mathrm{Sr}) \mathrm{Ga}(\mathrm{Mg}) \mathrm{O}_{3-\delta}\right)$, which is accounted for by strong Coulomb interactions between tetravalent metal cations and oxygen ions in the $\mathrm{M}^{4+}-\mathrm{O}-\mathrm{Mg}^{2+}$ или $\mathrm{M}^{2+}-\mathrm{O}-\mathrm{M}^{4+}$ clusters [27]. However, such explanations are open to question since the changes in the structural parameters may be associated also with clustering and with the formation of oxygen vacancies. The conclusion about the emergence of cations with the
+4 charge on introduction of $\mathrm{Sr}$ and $\mathrm{Mg}$ is questionable also because in this case the ionic conductivity had to decrease or totally disappear, however no such phenomena are observed. Moreover, the disproportionation of trivalent cations is very unprofitable (except for $\mathrm{Mn}^{3+}$ ) for thermodynamic reasons. There is no unambiguous data directly pointing to an increase in the charge state of transition element atoms.

These rather urgent problems require unambiguous answers. In spite of a large body of data on this topic in their great majority the studies are empirical and random. The absence of systematic approach to the study of electron-ionic conductors within the context of "composition - structure property" hampers the interpretation of experimental results and does not permit their generalization. The data about the electron structure would allow an insight into the problem of electronic and ionic conductivity of doped lanthanum gallates.

Hence in this work we put forward an ingenious approach to solving the problem of electron structure of doped lanthanum gallate using the method of magnetic dilution. The changes in the valence and spin states of a transition element and also in the interatomic interactions may be recorded in the examination of concentration and temperature dependences of magnetic susceptibility. This property is strongly sensitive to any changes both in the states of atoms and in their close surrounding, as will be shown below.

The method of magnetic dilution, as any method, has some limits in the quantity of introduced paramagnetic element $(\sim 10$ at $\%)$. No doubt, in this concentration range we cannot expect relatively high conductivity. However, only in the diluted solutions containing paramagnetic atoms we can precisely find their electron structure (the character of interatomic interactions, valence and spin states of transition element atoms). An increase in concentration results in cooperative effects complicating the pattern as a whole and making impossible the detailed examination of all the types of short range interactions in the systems.

Within this approach we studied a large number of systems based on lanthanum gallate containing strontium and transition elements [57-63].

The aim of this work was to calculate the fractions of single chromium atoms and clusters for the $\mathrm{La}_{1-}$ ${ }_{0.2 x} \mathrm{Sr}_{0.2 x} \mathrm{Cr}_{x} \mathrm{Ga}_{1-1.2 x} \mathrm{Mg}_{0.2 x} \mathrm{O}_{3-\delta}$ solid solutions $(0.01 \leq x \leq 0.1)$ and to examine the temperature dependences of the susceptibility for the solid solutions with the ratio of $\mathrm{Cr}: \mathrm{Sr}: \mathrm{Mg}=$ $5: 1: 1$ remaining constant over the whole concentration range. For comparison we used the solid solutions based on lanthanum gallate studied earlier. They contained only chromium, $\mathrm{LaCr}_{x} \mathrm{Ga}_{1-x} \mathrm{O}_{3}$ (Cr) [57], and chromim together with strontium in various ratios $-\mathrm{La}_{1-0.2 x} \mathrm{Sr}_{0.2 x} \mathrm{Cr}_{x} \mathrm{Ga}_{1-x} \mathrm{O}_{3-\delta}(\mathrm{Cr}: \mathrm{Sr}=$ 5:1) [58] and $\mathrm{La}_{1-0.5 x} \mathrm{Sr}_{0.5 x} \mathrm{Cr}_{x} \mathrm{Ga}_{1-x} \mathrm{O}_{3-\delta}(\mathrm{Cr}: \mathrm{Sr}=2: 1)$ [60].

\section{EXPERIMENTAL}

\subsection{Synthesis}

The $\mathrm{La}_{1-0.2 x} \mathrm{Sr}_{0.2 x} \mathrm{Cr}_{x} \mathrm{Ga}_{1-1.2 x} \mathrm{Mg}_{0.2 x} \mathrm{O}_{3-\delta}(0.01 \leq x \leq 0.1)$ solid solutions were obtained by the sol-gel method. We used special pure grade $\mathrm{La}_{2} \mathrm{O}_{3}$ and $\mathrm{Ga}_{2} \mathrm{O}_{3}$; analytical pure grade strontium carbonate; chromium oxide was obtained by reducing stoichiometric quantities of analytical pure grade ammonium bichromate with hydrogen peroxide in acid me- 
dium. The starting components were dissolved in nitric acid on heating. The resulting solution was cooled and neutralized with ammonium hydroxide to $\mathrm{pH} \sim 7$. Then we added citric acid and ethylene glycol as recommended in [29]. Amount of citric acid and ethylene glycol was calculated by the formula:

$$
n=\sum_{i} n_{i} v_{i}
$$

where $n_{i}$ - charge of cation metal; $v_{i}$ - number of moles of the metal.

The obtained gel was decomposed on heating in a furnace with the temperature being increased at a rate of $4^{\circ} \mathrm{C}$ per minute from 100 to $800^{\circ} \mathrm{C}$ (the furnace was heated from room temperature to $100^{\circ} \mathrm{C}$ as the current was switched on). A highly dispersed powder was pressed into pellets and sintered in air at $1450^{\circ} \mathrm{C}$ for $50 \mathrm{~h}$. The time of sintering for obtaining single phase samples was determined by the data of $\mathrm{X}$-ray analysis. The magnetic susceptibility remaining constant after sintering for additional 10 hours suggests that the obtained solid solutions are close to equilibrium distribution of paramagnetic atoms.

\subsection{Materials Characterisation}

The X-ray analysis was carried out on a URS-50 N diffractometer using $\mathrm{CuK}_{\alpha}$ emission. The contents of chromium, strontium, and magnesium was determined by Roentgen fluorescent and atom emission analyses. The data of both methods were in good agreement and the accuracy was no less than $2 \%$ from the value of $x$ in the solid solution formula.

The magnetic susceptibility of the solid solutions was measured by Faraday method in the temperature range 77 $400 \mathrm{~K}$ at 16 fixed temperatures. The accuracy of relative measurements was $1 \%$. The paramagnetic component of magnetic susceptibility was calculated with respect to the susceptibility of lanthanum gallate measured over the same temperature range.

\section{RESULTS AND DISCUSSION}

\subsection{Structural Data}

By the data of X-ray analysis all the obtained $\mathrm{La}_{1-}$ $0.2 x \mathrm{Sr}_{0.2 x} \mathrm{Cr}_{x} \mathrm{Ga}_{1-1.2 x} \mathrm{Mg}_{0.2 x} \mathrm{O}_{3-\delta}(0.01 \leq x \leq 0.1)$ solid solutions are single phase with cubic lanthanum gallate structure.

\subsection{Chemical Analysis}

The chemical analysis of the ceramics shows a certain shift in the composition after sintering, but the ratio of $\mathrm{Cr}: \mathrm{Sr}: \mathrm{Mg}$ remains close to 5:1:1. The importance of chemical analysis is associated with the fact that on sintering at high temperature the shift in the composition is inevitable, and this influences the accuracy of calculations of paramagnetic component of magnetic susceptibility, since it is calculated per mole of paramagnetic atoms.

\subsection{Experimental Magnetic Data}

By the results of magnetic susceptibility measurements we plotted the temperature and concentration dependences of $\chi_{C r}$. Let us examine the concentration dependence of paramagnetic component of magnetic susceptibility for the systems with $\mathrm{Cr}: \mathrm{Sr}=5: 1$ and $\mathrm{Cr}: \mathrm{Sr}: \mathrm{Mg}=5: 1: 1$ (Fig. 1).

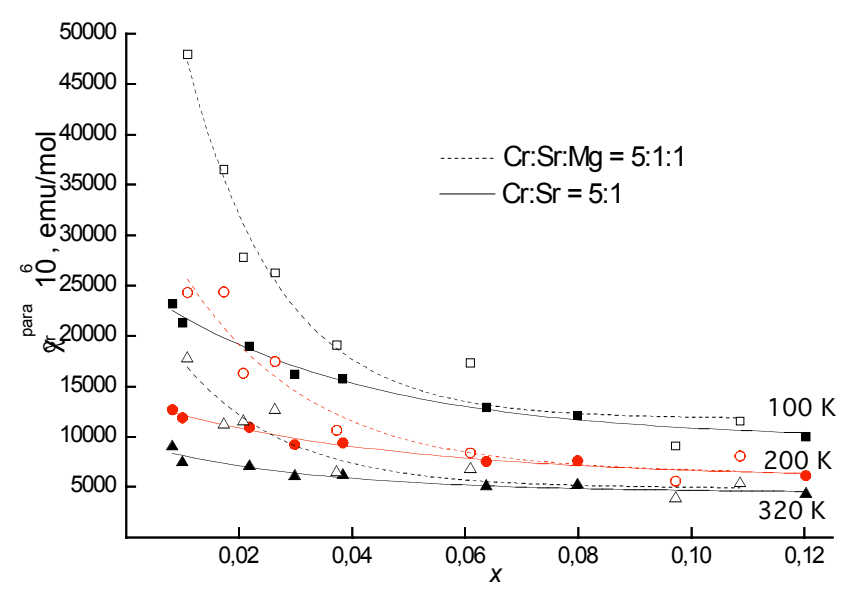

Fig. (1). Plot of paramagnetic component of magnetic susceptibility calculated per $1 \mathrm{~mol}$ of chromium atoms vs. chromium concentration for $\mathrm{La}_{1-0.2 x} \mathrm{Sr}_{0.2 x} \mathrm{Cr}_{x} \mathrm{Ga}_{1-x} \mathrm{O}_{3-\delta}$ and $\mathrm{La}_{1-0.2 x} \mathrm{Sr}_{0.2 x} \mathrm{Cr}_{x} \mathrm{Ga}_{1-}$ $1.2 x \mathrm{Mg}_{0.2 x} \mathrm{O}_{3-\delta}$ for 100,200 and $320 \mathrm{~K}$.

For all the temperatures the isotherms are almost coinciding given the chromium concentration $x>0.06$. This points to similar types of interatomic interactions and of atom states in this concentration region. An essential divergence of isotherms is observed only in the region of small chromium concentrations, which could testify for a direct influence of magnesium as a doping agent on the short range interactions between chromium atoms.

In Fig. (2) we give concentration dependences for three systems: $\mathrm{Cr}, \mathrm{Cr}: \mathrm{Sr}=5: 1$, and $\mathrm{Cr}: \mathrm{Sr}: \mathrm{Mg}=5: 1: 1$. There is no doubt that in $\mathrm{LaCr}_{x} \mathrm{Ga}_{1-x} \mathrm{O}_{3}$ only $\mathrm{Cr}(\mathrm{III})$ is present, and since the isotherms for $\mathrm{Cr}: \mathrm{Sr}=5: 1$, and $\mathrm{Cr}: \mathrm{Sr}: \mathrm{Mg}=5: 1: 1$ coincide with the isotherms for $\mathrm{LaCr}_{x} \mathrm{Ga}_{1-x} \mathrm{O}_{3}$ over a wide range of concentrations we can suggest that chromium does not change its valence state and remains trivalent. Otherwise, if we had a partial or complete oxidation of $\mathrm{Cr}$ (III) to $\mathrm{Cr}$ (IV) in the systems with $\mathrm{Sr}$ and (or) $\mathrm{Mg}$, the isotherms of magnetic

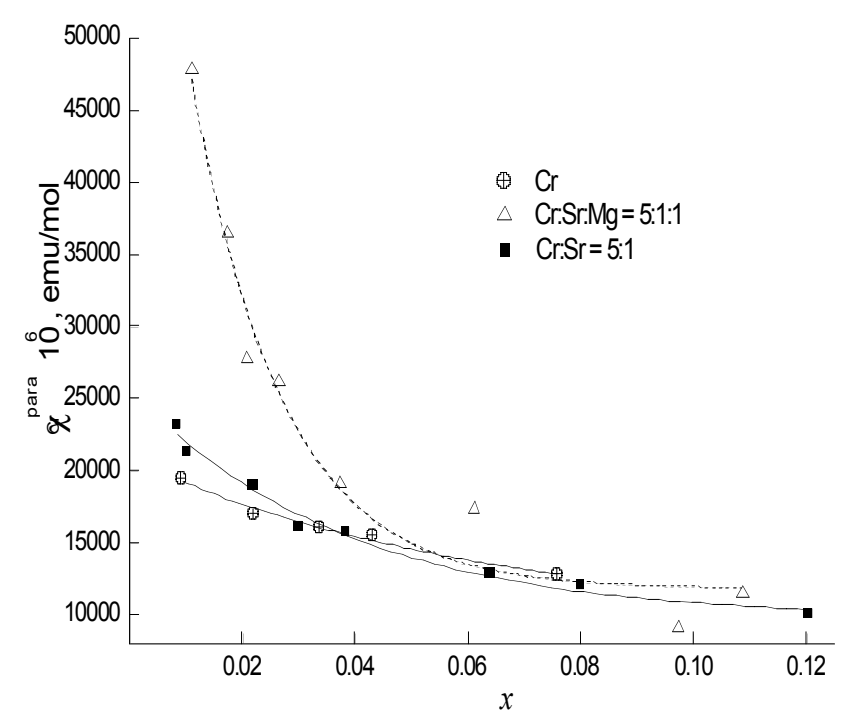

Fig. (2). Plot of paramagnetic component of magnetic susceptibility calculated per $1 \mathrm{~mol}$ of chromium atoms vs. chromium concentration for $\mathrm{LaCr}_{x} \mathrm{Ga}_{1-x} \mathrm{O}_{3}, \quad \mathrm{La}_{1-0.2 x} \mathrm{Sr}_{0.2 x} \mathrm{Cr}_{x} \mathrm{Ga}_{1-x} \mathrm{O}_{3-\delta}$ and $\mathrm{La}_{1-}$ $0.2 x \mathrm{Sr}_{0.2 x} \mathrm{Cr}_{x} \mathrm{Ga}_{1-1.2 x} \mathrm{Mg}_{0.2 x} \mathrm{O}_{3-\delta}$ for $160 \mathrm{~K}$. 
susceptibility would lay substantially lower than the isotherms for $\mathrm{LaCr}_{x} \mathrm{Ga}_{1-x} \mathrm{O}_{3}$, as was found for $\mathrm{Y}_{0.9} \mathrm{Ca}_{1.1} \mathrm{Cr}_{y} \mathrm{Al}_{1 \text { - }}$ ${ }_{y} \mathrm{O}_{4-\delta}$ [64].

For the systems with $\mathrm{Cr}: \mathrm{Sr}=5: 1$ and $\mathrm{Cr}: \mathrm{Sr}: \mathrm{Mg}=5: 1: 1$ there is only a certain increase in the magnetic susceptibility in the range of low concentrations, which can be accounted for either by a partial transition of $\mathrm{Cr}$ (III) to $\mathrm{Cr}$ (II), or by the formation of aggregates of chromium atoms having a large magnetic moment and thus increasing the susceptibility.

Extrapolating the effective magnetic moment to the infinite dilution $(x \rightarrow 0)$ for every temperature studied we obtained the plot given in Fig. (3).

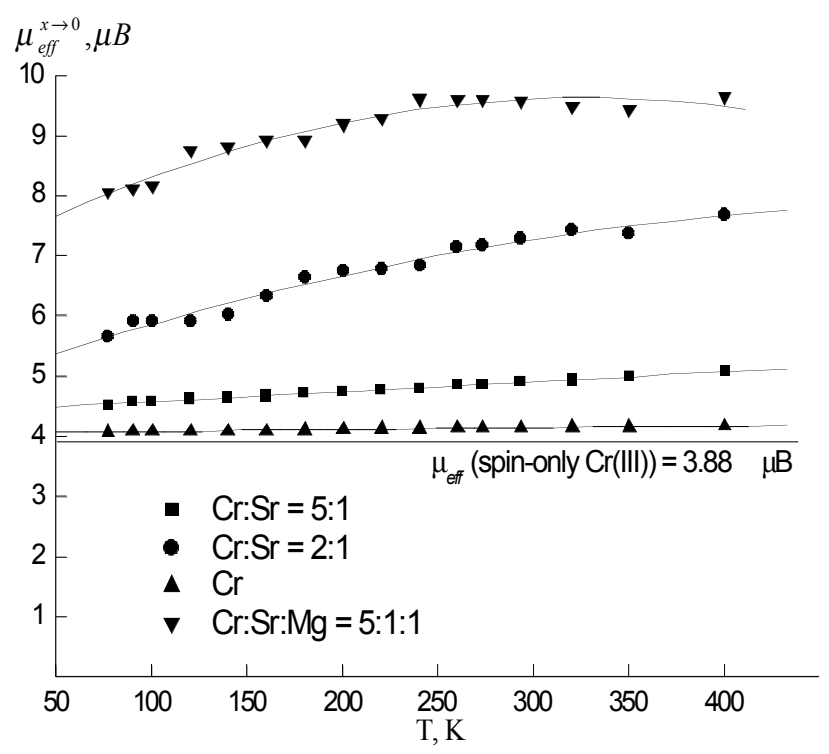

Fig. (3). Plot of effective magnetic moment vs. temperature at the infinite dilution for the systems: $\mathrm{LaCr}_{x} \mathrm{Ga}_{1-x} \mathrm{O}_{3} \quad(\mathrm{Cr}), \mathrm{La}_{1}$ ${ }_{0.2 x} \mathrm{Sr}_{0.2 x} \mathrm{Cr}_{x} \mathrm{Ga}_{1-x} \mathrm{O}_{3-\delta} \quad(\mathrm{Cr}: \mathrm{Sr}=5: 1), \quad \mathrm{La}_{1-0.5 x} \mathrm{Sr}_{0.5 x} \mathrm{Cr}_{x} \mathrm{Ga}_{1-x} \mathrm{O}_{3-\delta}$ (Cr:Sr=2:1), $\mathrm{La}_{1-0.2 x} \mathrm{Sr}_{0.2 x} \mathrm{Cr}_{x} \mathrm{Ga}_{1-1.2 x} \mathrm{Mg}_{0.2 x} \mathrm{O}_{3-\delta}(\mathrm{Cr}: \mathrm{Sr}: \mathrm{Mg}=5: 1: 1)$.

Whenever we deal with regular solid solutions, as complex oxides with perovskite like structure usually are, at infinite dilution there must be only single atoms left, no matter what was the clustering as the concentration increased. Therefore we were to obtain the effective magnetic moments corresponding to single chromium(III) atoms $-\mu_{\text {eff }}=3.88$ BM. For $\mathrm{LaCr}_{x} \mathrm{Ga}_{1-x} \mathrm{O}_{3}$ we do obtain $\mu_{\text {eff }} \sim 4.00 \mathrm{BM}$, which does not depend on temperature (the ground term of $\mathrm{Cr}$ (III) ${ }^{4} \mathrm{~A}_{2 \mathrm{~g}}$ ).

The effective magnetic moments at infinite dilution for the systems with $\mathrm{Cr}: \mathrm{Sr}=5: 1, \mathrm{Cr}: \mathrm{Sr}=2: 1$, and $\mathrm{Cr}: \mathrm{Sr}: \mathrm{Mg}=$ $5: 1: 1$ is substantially higher than the spin only values and do not correspond to any valence state of chromium atoms:

$$
\begin{gathered}
\mathrm{Cr}(\mathrm{II}), d^{4},{ }^{5} \mathrm{E}_{\mathrm{g}}, \mu_{e f f} \sim 4.90 \mathrm{BM} ; \\
\mathrm{Cr}(\mathrm{III}), d^{3},{ }^{4} \mathrm{~A}_{2 \mathrm{~g}}, \mu_{e f f} \sim 3.88 \mathrm{BM} ; \\
\mathrm{Cr}(\mathrm{IV}), d^{2},{ }^{3} \mathrm{~T}_{1 \mathrm{~g}}, \mu_{e f f} \sim 2.83 \mathrm{BM} .
\end{gathered}
$$

Moreover, there is a distinct temperature dependence of $\mu_{e f f}$ at $x \rightarrow 0$. The effective magnetic moments greater than the only spin values suggest the emergence of strong aggregates of chromium atoms, which do not disintegrate even at infinite dilution. As early as in 1979 we were able to show that a dimer cluster remaining at the infinite dilution of a solid solution must have a bond energy of about $100 \mathrm{~kJ} / \mathrm{mol}$ [65]. This suggests that the formation of clusters is determined by thermodynamic reasons rather than magnetic exchange interactions, their energy rarely exceeding $1 \mathrm{~kJ} / \mathrm{mol}$.

As follows from Fig. (3), for each type of the system distinguishing by the qualitative composition the structure of clusters is different, since the effective magnetic moments differ. The obtained data clearly testify for strontium and (or) magnesium (and also oxygen vacancies located in the vicinity of them) enter the composition of these clusters.

The unusual temperature dependence and the absolute values of magnetic moments make it impossible to describe these clusters within Heizenberg-Dirac-van-Vleck model [66]. According to this model the effective magnetic moment of a cluster linked ferromagnetically may either decrease as the temperature increases, or remain constant. Whereas for an antiferromagnetic cluster $\mu_{\text {eff }}$ increases as the temperature increases, but does not exceed the spin only value of a single atom.

On the one hand, we have the dependence, its temperature run being typical for an antiferromagnetic cluster, on the other hand, the absolute values of the moment point to a ferromagnetic exchange. There seems to be a double exchange $[67,68]$ in the clusters as is described for the $\mathrm{Cr}: \mathrm{Sr}=5: 1$ and $\mathrm{Cr}: \mathrm{Sr}=2: 1$ systems [63]. It follows from [63] that at the infinite dilution for $\mathrm{Cr}: \mathrm{Sr}=2: 1$ there remain only some clusters (we called them clusters $\mathrm{X}$ ), i.e. their fraction is equal to 1 , and in the $\mathrm{Cr}: \mathrm{Sr}=5: 1$ system the magnetic moments correspond to $20 \%$ of clusters $\mathrm{X}$ and $80 \%$ of monomers.

Returning to Fig. (2), where the isotherms coincide after $x>0.06$, we can conclude that for the $\mathrm{Cr}: \mathrm{Sr}: \mathrm{Mg}=5: 1: 1$ system in this concentration range the same clusters will exist as in the $\mathrm{Cr}: \mathrm{Sr}=5: 1$.

The high values of $\mu_{\text {eff }}$ for the $\mathrm{Cr}: \mathrm{Sr}: \mathrm{Mg}=5: 1: 1$ system and their temperature dependence also cannot be described even taking into account the clusters $\mathrm{X}$ from previous systems. Hence we suggested that here at the infinite dilution there are only clusters $\mathrm{Y}$ of another nature than clusters $\mathrm{X}$.

\subsection{Theoretical Study}

We calculated the fractions of various clusters on the basis of diluted solution model. It suggests that in a diluted solid solution the magnetic susceptibility is determined as a sum of the susceptibilities of single atoms (monomers) and various clusters, mostly small, multiplied by their fraction in a particular solid solution $\left(a_{i}\right)$ :

$$
\chi=\sum_{i} a_{i} \chi_{i}
$$

The fractions of clusters and single atoms are constant for every concentration of the solid solution and obey equation (2):

$$
\sum_{j} a_{j}=1
$$

In the $\mathrm{La}_{1-0.2 x} \mathrm{Sr}_{0.2 x} \mathrm{Cr}_{x} \mathrm{Ga}_{1-1.2 x} \mathrm{Mg}_{0.2 x} \mathrm{O}_{3-\delta}$ doped gallate we suppose that there are single chromium atoms, antiferromagnetic dimers, antiferromagnetic linear trimers, clusters $\mathrm{X}$ 
[63], and clusters $\mathrm{Y}$ determining an unusual temperature dependence of effective magnetic moment at the infinite dilution (Fig. 3).

Thus we obtain the equation for calculating the theoretical susceptibility:

$$
\begin{aligned}
& \chi_{c r}^{\text {para }}=a_{c l Y} \chi_{c l Y}+a_{c l X} \chi_{c l X}+a_{d i m} \chi_{d i m}+a_{t r i} \chi_{t r i}+ \\
& \left(1-a_{c l X}-a_{d i m}-a_{t r i}-a_{c l Y}\right) \chi_{\text {mono }}
\end{aligned}
$$

For the effective magnetic moment equation (3) transforms into:

$$
\begin{aligned}
& \mu_{C r}^{2}=a_{c l Y} \mu_{c l Y}^{2}+a_{c l X} \mu_{c l X}^{2}+a_{d i m} \mu_{d i m}^{2}+a_{t r i} \mu_{t r i}^{2}+ \\
& \left(1-a_{c l X}-a_{d i m}-a_{t r i}-a_{c l Y}\right) \mu_{m o n o}^{2}
\end{aligned} .
$$

Here $\chi_{C r}$ and $\mu_{C r}$ are the experimental values of paramagnetic component of magnetic susceptibility and of effective magnetic moment respectively. $\mu_{\text {mono }}$ was taken as a spin only value for $\mathrm{Cr}$ (III). $\mu_{\text {dim }}$ and $\mu_{t r i}$ were calculated by Heisenberg-Dirac-van Vleck (HDVV) model for two and three interacting spins.

In general the Hamiltonian of the system of interacting spins without considering Zeeman interaction is given by equation (5):

$$
\hat{H}=-2 \sum_{i<j} J \hat{S}_{i} \hat{S}_{j},
$$

where $J$ is the exchange parameter, $S_{i(j)}$ - the spin $i(j)$ operator. We can obtain analytical or numerical solutions of Hamiltonian and find its eigenvalues - the energies of the spin levels - depending on the number of spins in a cluster and on its geometry. The energy is determined both by the total spin of the system $(S)$ and by the spins of separate atoms $\left(S_{i}\right)$ and for a dimer it appears as equation (6):

$$
E_{d}\left(J_{d}, S\right)=-J_{d}\left[S(S+1)-S_{1}\left(S_{1}+1\right)-S_{2}\left(S_{2}+1\right)\right] .
$$

The energy of the spin levels, $E(J, S)$ is associated with the effective magnetic moment calculated per mole of metal atoms by van Vleck equation (7) [66].

$$
\mu_{e f f}^{2}=\frac{g^{2} \sum_{S} S(S+1)(2 S+1) e^{-\frac{E(J, S)}{k T}}}{n \sum_{S}(2 S+1) e^{-\frac{E(J, S)}{k T}}},
$$

where $n$ is the number of paramagnetic atoms in a cluster; $k$ is Boltzmann constant; $T$ - absolute temperature; $g$ - Lande factor.

Therefore for an $S_{1}=S_{2}=3 / 2, g_{1}=g_{2}=2$ couple with regard to $x=J_{d} / k T$ we obtain

$$
\mu_{d i m}^{2}=\frac{g^{2}}{2} \frac{84 e^{12 x}+30 e^{6 x}+6 e^{2 x}}{7 e^{12 x}+5 e^{6 x}+3 e^{2 x}+1} .
$$

Let us consider the susceptibility of a trimer in more details. We took into account the case of a chain of 2-1-3 atoms (the figures correspond to the numbers of atoms), $C_{\infty v}$ symmetry. For a homonuclear $\mathrm{Cr}$ (III)-Cr(III)-Cr(III) trimer we have one exchange parameter $J_{t}$. The Spin-Hamiltonian without considering Zeeman interaction and its eigenvalues are:

$$
\begin{aligned}
& \hat{H}=-2 J_{t}\left(\hat{S}_{1} \hat{S}_{2}+\hat{S}_{1} \hat{S}_{3}\right) \\
& E_{t}\left(J_{t}, S\right)=-J_{t}\left[S(S+1)-S_{23}\left(S_{23}+1\right)-S_{1}\left(S_{1}+1\right)\right],
\end{aligned}
$$

where according to the rule of adding the moments the total spin $(S)$ and intermediate $\left(S_{23}\right)$ spin take the values:

$$
\begin{aligned}
& S=S_{1}+S_{23}, S_{1}+S_{23}-1, \ldots,\left|S_{1}-S_{23}\right|, \\
& S_{23}=S_{2}+S_{3}, S_{2}+S_{3}-1, \ldots,\left|S_{2}-S_{3}\right| .
\end{aligned}
$$

Using Van-Vleck equation it is easy to obtain the final expression for the magnetic moment of three atoms $S_{1}=S_{2}=$ $S_{3}=3 / 2$ linked by exchange with $g_{1}=g_{2}=g_{3}=2, y=J_{t} / k T$ :

$$
\begin{aligned}
& 247,5 e^{21 y}+126 e^{18 y}+52,5 e^{15 y}+141 e^{12 y}+52,5 e^{11 y}+ \\
& \mu_{t r i}^{2}=\frac{g^{2}}{3} \frac{15 e^{10 y}+1,5 e^{7 y}+15 e^{6 y}+52,5 e^{5 y}+1,5 e^{3 y}+15}{10 e^{21 y}+8 e^{18 y}+6 e^{15 y}+12 e^{12 y}+6 e^{11 y}+} \\
& 4 e^{10 y}+2 e^{7 y}+4 e^{6 y}+6 e^{5 y}+2 e^{3 y}+4
\end{aligned}
$$

The only difference from the case of dimers is in the fact that we sum up over the intermediate spin to take into account the multiplicity of spin multiplet degeneracy with the same total spin values.

In our calculation we varied the fractions of clusters and monomers and $J_{t}$, accepting $J_{d}=-12 \mathrm{~cm}^{-1}$ as in [57]. $\mu_{c l Y}$ were taken from the dependence of the effective magnetic moment at the infinite dilution for the $\mathrm{Cr}: \mathrm{Sr}: \mathrm{Mg}=5: 1: 1$ system. The parameters were considered as optimal on condition that $\sum_{i} \sum_{j}\left(\chi_{i j}^{\text {calc }}-\chi_{i j}^{\text {exp }}\right)^{2} \rightarrow 0$, where we sum up over all the concentrations $(i)$ and temperatures $(j) ; \chi_{i j}{ }^{\text {calc }}, \chi_{i j}{ }^{\text {exp }}$ are calculated and experimental magnetic susceptibilities.

We found $J_{t}=-20 \mathrm{~cm}^{-1}$. The difference between the calculated and experimental values of magnetic susceptibility did not exceed $2 \%$ (Fig. 4).

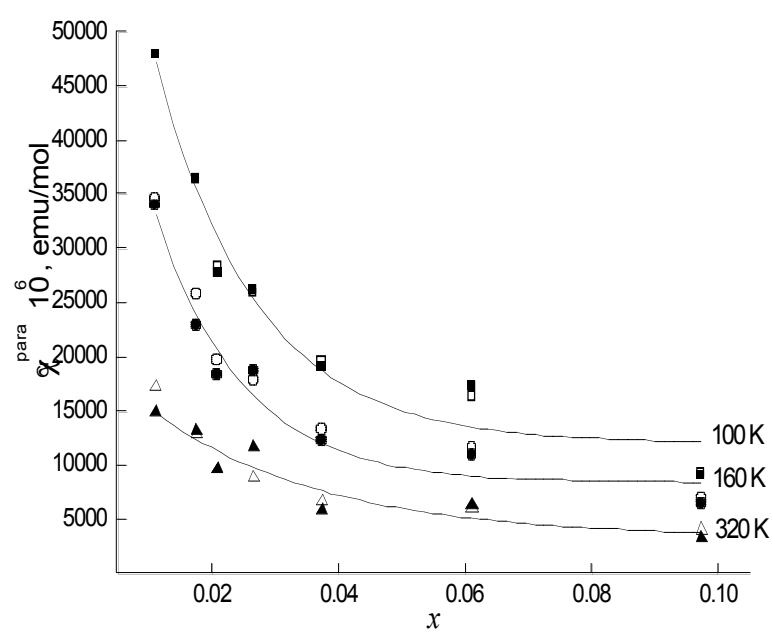

Fig. (4). Theoretical (open symbol) and experimental (close symbol) values of paramagnetic component of magnetic susceptibility calculated per $1 \mathrm{~mol}$ of chromium atoms vs. chromium concentration for $\mathrm{La}_{1-0.2 x} \mathrm{Sr}_{0.2 x} \mathrm{Cr}_{x} \mathrm{Ga}_{1-1.2 x} \mathrm{Mg}_{0.2 x} \mathrm{O}_{3-\delta}$ (Cr:Sr:Mg=5:1:1) for three temperatures: $100 ; 160 ; 320 \mathrm{~K}$. 
We tried also to exclude from our calculations one or other type of paramagnetic particles - monomers or clusters, but this resulted in an essential divergence between the data of experiment and theory (up to 6\%), hence we concluded that our approach is the most valid.

The influence of magnesium on the number of various clusters of chromium atoms can be traced upon comparing the concentration dependences of the cluster fractions for the $\mathrm{Cr}: \mathrm{Sr}=5: 1$ and $\mathrm{Cr}: \mathrm{Sr}: \mathrm{Mg}=5: 1: 1$ systems (Figs. 5, 6).

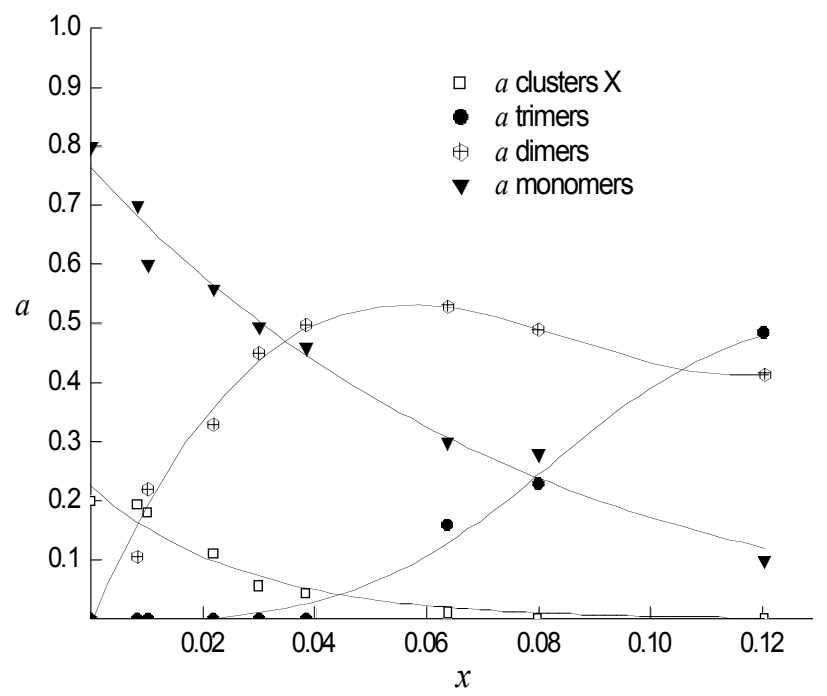

Fig. (5). Fractions of clusters and single chromium atoms vs. chromium concentration for $\mathrm{La}_{1-0.2 x} \mathrm{Sr}_{0.2 x} \mathrm{Cr}_{x} \mathrm{Ga}_{1-x} \mathrm{O}_{3-\delta}[63]$.

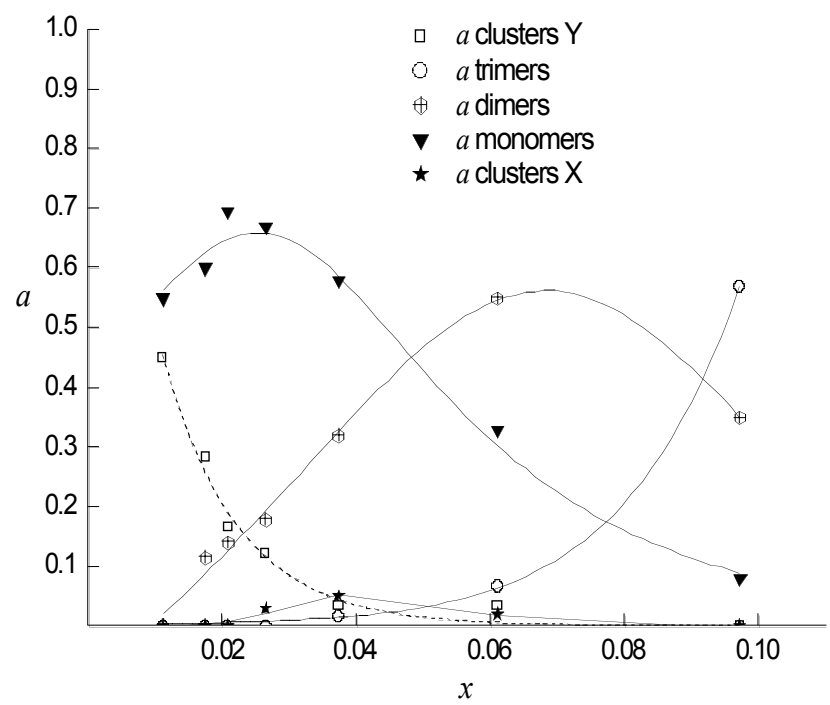

Fig. (6). Fractions of clusters and single chromium atoms vs. chromium concentration for $\mathrm{La}_{1-0.2 x} \mathrm{Sr}_{0.2 x} \mathrm{Cr}_{x} \mathrm{Ga}_{1-1.2 x} \mathrm{Mg}_{0.2 x} \mathrm{O}_{3-\delta}$.

The special features of the changes in the cluster fractions depend both on qualitative and quantitative composition of the system. For the solutions containing neither strontium nor magnesium, $\mathrm{LaCr}_{x} \mathrm{Ga}_{1-x} \mathrm{O}_{3}$, we have a typical pattern of the dilution of antiferromagnets - as the concentration of paramagnetic component increases, the fraction of monomers decreases, the fraction of antiferromagnetic dimers increases [57].
The introduction of chromium and strontium into lanthanum gallate with the ratio $\mathrm{Cr}: \mathrm{Sr}=5: 1$ results in clusters $\mathrm{X}$ apart from monomers, dimers, and increasing fraction of trimers. These clusters $\mathrm{X}$ have no less than 4 paramagnetic atoms, are somehow associated with the vacancies in the sublattice of oxygen, and have a distinct ferromagnetic component in the exchange. The introduction of magnesium in addition to strontium results in some other clusters - Y even greater than $\mathrm{X}$. Both types of clusters are preserved at the infinite dilution, but their fraction decreases as the concentration increases. This points again to the fact that strontium atoms and vacancies associated with them are included into these clusters with a strong bonding. We can assume that as concentration increases, the additional chromium atoms become located near the vacancies thus behaving like monomers, their fraction increasing as the concentration increases. Then the dimer and trimer clusters appear with antiferromagnetic exchange.

The clusters with a distinct ferromagnetic component in the exchange may be accounted for by the double exchange $[67,68]$ between heterovalent chromium atoms $\mathrm{Cr}(\mathrm{III}) \mid \mathrm{Cr}$ (II). Introduction of strontium or magnesium can result not only in oxygen vacancies (one vacancy per two strontium or magnesium atoms) but also in "extra" electrons at the site of vacancy. This "extra" electron can pass from the vacancy to the adjacent chromium(III) atom thus resulting in the reduction of chromium(III) to $\mathrm{Cr}$ (II). Migration of an electron from one paramagnetic center to another may result in a strong ferromagnetism. Such an assumption excludes $\mathrm{Cr}(\mathrm{IV})$, even though the exchange $\mathrm{Cr}$ (III) $\mid \mathrm{Cr}$ (IV) also would be ferromagnetic, because we would never obtain oxygen conductivity in these systems and the magnetic data testify strongly against this.

The measurements of impedance spectra of these systems confirmed that they show a transfer from purely electronic to ionic conductivity in the temperature range of about 300$400^{\circ} \mathrm{C}$ like in [60]. More detailed studies of impedance will be published later.

\subsection{Impedance Spectroscopy}

All samples were characterized by impedance spectroscopy from $3 \mathrm{MHz}$ to $0.1 \mathrm{~Hz}$ at the temperature range $50-800^{\circ} \mathrm{C}$. Density of all the samples was close to theoretical value. Typical spectra at Cole-Cole plots and equivalent electrical circuit is given in Fig. (7) for various temperatures. Impedance spectra consists of two parts: a bulk semicircle (with the bulk resistance $\left(R_{\mathrm{b}}\right)$ and constant phase element $\left.\left(Q_{\mathrm{b}}\right)\right)$ and a grain-boundary semicircle (with the grain-boundary resistance $\left(R_{\mathrm{gb}}\right)$ and constant phase element $\left.\left(\mathrm{Q}_{\mathrm{gb}}\right)\right)$ [69]. This equivalent circuit gives the best approximation for both bulk and grain-boundary parts for all the temperatures.

The plot of logarithm of the bulk conductivity of the grains vs reverse temperature is given in Fig. (8) for the systems with various contents of strontium $-\mathrm{Cr}: \mathrm{Sr}=2: 1$ and $\mathrm{Cr}: \mathrm{Sr}=5: 1$, for the system with chromium only $\left(\mathrm{LaCr}_{x} \mathrm{Ga}_{1}\right.$. $\left.{ }_{x} \mathrm{O}_{3}(\mathrm{Cr})\right)$ and the system with strontium and magnesium, $\mathrm{Cr}: \mathrm{Sr}: \mathrm{Mg}=5: 1: 1$, the quantity of chromium is given by the data of chemical analysis. The conductivity is minimal for $\mathrm{LaCr}_{x} \mathrm{Ga}_{1-x} \mathrm{O}_{3}$, in all the other cases a break is observed in the temperature dependence, the conductivities in both parts being greater than for $\mathrm{LaCr}_{x} \mathrm{Ga}_{1-x} \mathrm{O}_{3}$. This seems to be asso- 
ciated with ionic conductivity; the break must be associated with the predominance of ionic transport at higher temperatures.

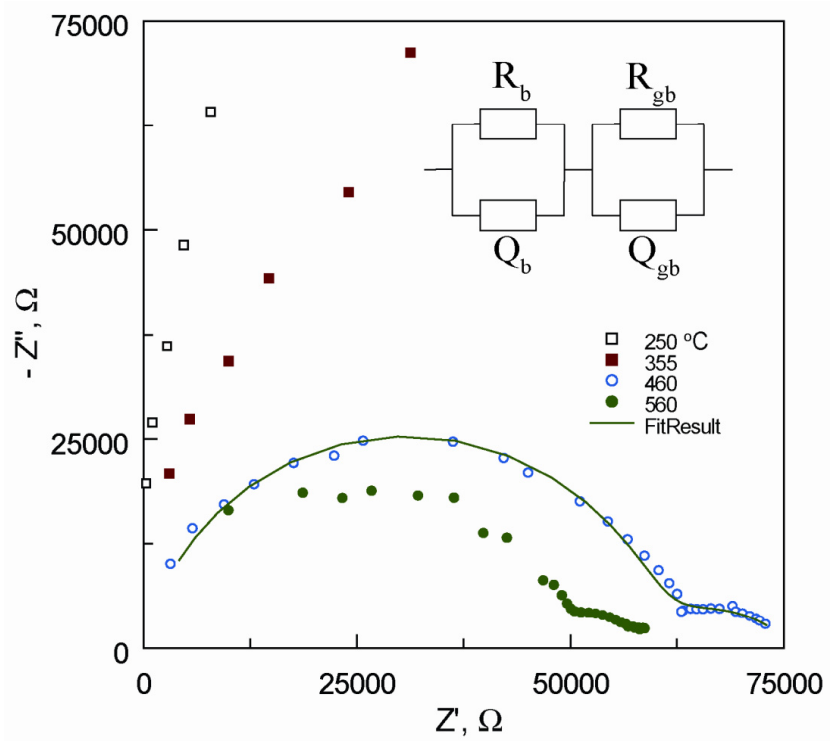

Fig. (7). Impedance spectra as Cole-Cole plots, the simulation and equivalent circuit for $\mathrm{La}_{1-0.2 x} \mathrm{Sr}_{0.2 x} \mathrm{Cr}_{x} \mathrm{Ga}_{1-1.2 x} \mathrm{Mg}_{0.2 x} \mathrm{O}_{3-\delta}(x=0.0112)$.

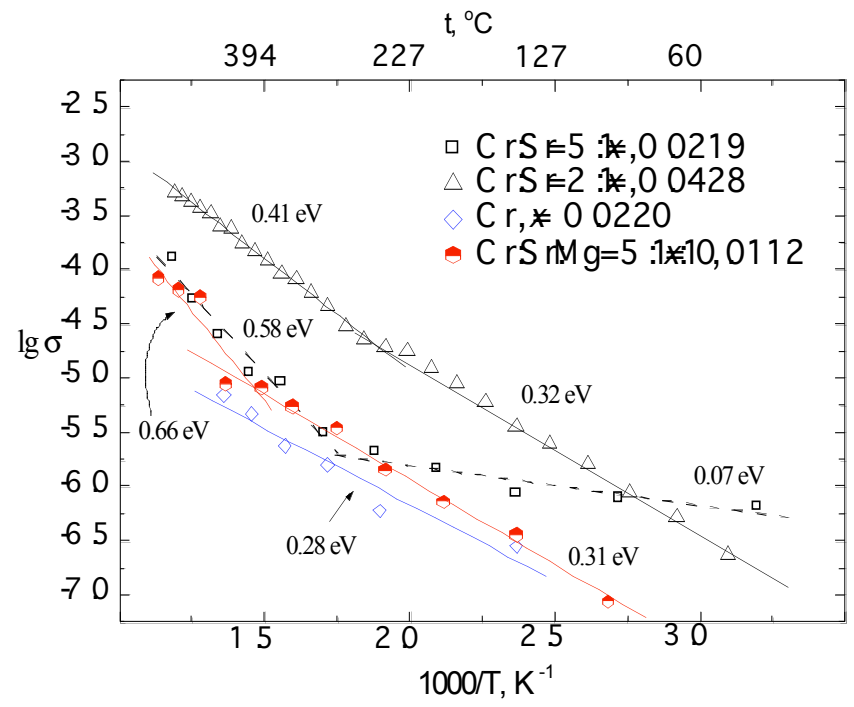

Fig. (8). Arrhenius plots of $\mathrm{La}_{1-0.2 x} \mathrm{Sr}_{0.2 x} \mathrm{Cr}_{x} \mathrm{Ga}_{1-x} \mathrm{O}_{3-\delta}(\mathrm{Cr}: \mathrm{Sr}=5: 1)$, $\mathrm{La}_{1-0.5 x} \mathrm{Sr}_{0.5 x} \mathrm{Cr}_{x} \mathrm{Ga}_{1-x} \mathrm{O}_{3-\delta}(\mathrm{Cr}: \mathrm{Sr}=2: 1), \mathrm{LaCr}_{x} \mathrm{Ga}_{1-x} \mathrm{O}_{3}(\mathrm{Cr})$ and $\mathrm{La}_{1-}$ $0.2 x \mathrm{Sr}_{0.2 x} \mathrm{Cr}_{x} \mathrm{Ga}_{1-1.2 x} \mathrm{Mg}_{0.2 x} \mathrm{O}_{3-\delta}(\mathrm{Cr}: \mathrm{Sr}: \mathrm{Mg}=5: 1: 1)$.

\section{CONCLUSIONS}

Therefore we see that the introduction of magnesium into lanthanum gallate doped with strontium and chromium results in a distinct increase in the clustering of chromium atoms, which can be recognized only at low concentrations of the doping atoms. This may be attributed to the fact that magnesium atoms occupy the same sites as chromium, thus their influence on $d$-orbitals of the latter are stronger. Magnesium atoms providing for an essentially more ionic bond with oxygen than gallium atoms exert a strong polarizing effect on $p$-orbitals of oxygen. Therefore the bond between chromium atoms and oxygen become more covalent, which results in an increase in clustering. Chromium atoms in the system are only in the trivalent state.

\section{REFERENCES}

[1] Ishihara, T.; Matsuda, H.; Takita, Y. Doped $\mathrm{LaGaO}_{3}$ perovskite type oxide as a new oxide ionic conductor. J. Am. Chem. Soc., 1994, 116, 3801-3803.

[2] Kuroda, K.; Hashimoto, I.; Adachi, K.; Akikusa, J.; Tamou, Y.; Komada, N.; Ishihara, T.; Takita, Y. Characterization of solid oxide fuel cell using doped lanthanum gallate. Solid State Ionics, 2000, 132, 199-208.

[3] Du, Y.; Sammes, N.M. Fabrication of tubular electrolytes for solid oxide fuel cells using strontium- and magnesium-doped $\mathrm{LaGaO}_{3}$ materials. J. Eur. Ceram. Soc., 2001, 21, 727-735.

[4] Enoki, M.; Yan, J.; Matsumoto, H.; Ishihara, T. High oxide ion conductivity in $\mathrm{Fe}$ and $\mathrm{Mg}$ doped $\mathrm{LaGaO}_{3}$ as the electrolyte of solid oxide fuel cells. Solid State Ionics, 2006, 177, 2053-2057.

[5] Ishihara, T.; Tabuchi, J.; Ishikawa, S.; Yan, J.; Enoki, M.; Matsumoto, $\mathrm{H}$. Recent progress in $\mathrm{LaGaO}_{3}$ based solid electrolyte for intermediate temperature SOFCs. Solid State Ionics, 2006, 177, 1949-1953

[6] Jacobson, A.J. Materials for solid oxide fuel cells. Chem. Mater., 2010, 22, 660-674

[7] Skinner, S.J.; Kilner, J.A. Oxygen ion conductors. Materials Today, 2003, 30-37.

[8] Kajitani, M.; Matsuda, M.; Hoshikawa, A.; Oikawa, K.; Torii, S.; Kamiyama, T.; Izumi, F.; Miyake, M. Neutron diffraction study on lanthanum gallate perovskite compound series. Chem. Mater. 2003, 15, 3468-3473.

[9] Tas, A.C.; Majewski, P.J.; Aldinger, F. Chemical preparation of pure and strontium- and/or magnesium-doped lanthanum gallate powders. J. Am. Ceram. Soc., 2000, 83(12), 2954-2960.

[10] Datta, P.; Majewski, P.; Aldinger, F. Structural studies of Sr- and Mg-doped $\mathrm{LaGaO}_{3}$. J. Alloys Compd., 2007, 438, 232-237.

[11] Zheng, F.; Bordia, R.K.; Pederson, L.R. Phase constitution in $\mathrm{Sr}$ and $\mathrm{Mg}$ doped $\mathrm{LaGaO}_{3}$ system. Mater. Res. Bull., 2004, 39, 141155 .

[12] Jasiolek, G.; Dabkowska, H. X-ray emission studies of some Re$\mathrm{GaO}_{3}$ single crystals. J. Less Common Met., 1990, 160, 79-84.

[13] Wang, Y.; Liu, X.; Yao, G.-D.; Liebermann, R.C.; Dudley, M. High temperature transmission electron microscopy and X-ray diffraction studies of twinning and the phase transition at $145^{\circ} \mathrm{C}$ in $\mathrm{LaGaO}_{3}$. Mater. Sci. Eng., 1991, A132, 13-21.

[14] Kobayashi, J.; Tazoh, Y.; Sasaura, M.; Miyazawa, S. Structure analysis of lanthanum gallate. J. Mater. Res., 1991, 6(1), 97-100.

[15] Marti, W.; Fischer, P.; Altorfer, F.; Scheel, H.J.; Tadin, M. Crystal structure and phase transitions of orthorhombic and rhombohedral $\mathrm{RGaO}_{3}(\mathrm{R}=\mathrm{La}, \mathrm{Pr}, \mathrm{Nd})$ investigated by neutron powder diffraction. J. Phys.: Condens. Matter, 1994, 6, 127-135.

[16] Slater, P.R.; Irvine, J.T.S.; Ishihara, T.; Takita, Y. The structure of the oxide ion conductor $\mathrm{La}_{0.9} \mathrm{Sr}_{0.1} \mathrm{Ga}_{0.8} \mathrm{Mg}_{0.2} \mathrm{O}_{2.85}$ by powder neutron diffraction. Solid State Ionics, 1998, 107, 319-323.

[17] Slater, P.R.; Irvine, J.T.S.; Ishihara, T.; Takita, Y. Structure of lanthanum gallate electrolytes at high temperatures, vol. SOFC-VI, 1998, 387-396.

[18] Slater, P.R.; Irvine, J.T.S.; Ishihara, T.; Takita, Y. Hightemperature powder neutron diffraction study of the oxide ion conductor $\mathrm{La}_{0.9} \mathrm{Sr}_{0.1} \mathrm{Ga}_{0.8} \mathrm{Mg}_{0.2} \mathrm{O}_{2.85}$, J. Solid State Chem., 1998, 139, 135-143.

[19] Majewski, P.; Rozumek, M.; Tas, C.; Aldinger, F. Processing of $(\mathrm{La}, \mathrm{Sr})(\mathrm{Ga}, \mathrm{Mg}) \mathrm{O}_{3}$ solid electrolyte, J. Electroceram., 2002, 8, 6573.

[20] Feng, M.; Goodenough, J.B. Improved oxide electrolytes. Eur. J. Solid State Inorg. Chem., 1994, T31, 663.

[21] Lerch, M.; Boysen, H.; Hansen, T. High-temperature neutron scattering investigation of pure and doped lanthanum gallate. J. Phys. Chem. Solids, 2001, 62, 445-455.

[22] Wang, W.L.; Lu, H.Y. Twinning induced by the rhombohedral to orthorhombic phase transition in lanthanum gallate $\left(\mathrm{LaGaO}_{3}\right)$. Phys. Chem. Miner., 2006, 33(7), 435-444.

[23] Cheng, J.; Navrotsky, A. Energetics of magnesium, strontium, and barium doped lanthanum gallate perovskites. J. Solid State Chem., 2004, 177, 126-133. 
[24] Khan, M.S.; Islam, M.S.; Bates, D.R. Dopant substitution and ion migration in the $\mathrm{LaGaO}_{3}$-based oxygen ion conductor, J. Phys. Chem. B, 1998, 102, 3099-3104.

[25] Islam, M.S. Computer modelling of defects and transport in perovskite oxides. Solid State Ionics, 2002, 154-155, 75-85.

[26] Malavasi, L.; Fisher, C.A.J.; Islam, M.S. Oxide-ion and proton conducting electrolyte materials for clean energy applications: structural and mechanistic features. Chem. Soc. Rev., 2010, 39, 4370-4387.

[27] Kharton, V.V.; Viskup, A.P.; Yaremchenko, A.A.; Baker, R.T.; Gharbage, B.; Mather, G.C.; Figueiredo, F.M.; Naumovich, E.N.; Marques, F.M.B. Ionic conductivity of $\mathrm{La}(\mathrm{Sr}) \mathrm{Ga}(\mathrm{Mg}, \mathrm{M}) \mathrm{O}_{3-\delta}(\mathrm{M}=$ $\mathrm{Ti}, \mathrm{Cr}, \mathrm{Fe}, \mathrm{Co}, \mathrm{Ni})$ : effects of transition metal dopants. Solid State Ionics, 2000, 132, 119-130.

[28] Stevenson, J.W.; Armstrong, T.R.; Pederson, L.R.; Li, J.; Lewinsohn, C.A.; Baskaran, S. Effect of A-site cation nonstoichiometry on the properties of doped lanthanum gallate. Solid State Ionics, 1998, 113-115, 571-583.

[29] Polini, R.; Pamio, A.; Traversa, E. Effect of synthetic route on sintering behaviour, phase purity and conductivity of $\mathrm{Sr}-$ and $\mathrm{Mg}$ doped $\mathrm{LaGaO}_{3}$ perovskites. J. Eur. Ceram. Soc., 2004, 24, 13651370.

[30] Li, Z.-C.; Zhang, H.; Bergman, B.; Zou, X. Synthesis and characterization of $\mathrm{La}_{0.85} \mathrm{Sr}_{0.15} \mathrm{Ga}_{0.85} \mathrm{Mg}_{0.15} \mathrm{O}_{3-\delta}$ electrolyte by steric entrapment synthesis method. J. Eur. Ceram. Soc., 2006, 26, 23572364.

[31] Shi, M.; Xu, Y.; Liu, A.; Liu, N.; Wang, C.; Majewski, P.; Aldinger, F. Synthesis and characterization of Sr- and Mg-doped lanthanum gallate electrolyte materials prepared via the Pechini method. Mater. Chem. Phys., 2009, 114, 43-46.

[32] Datta, P.; Majewski, P.; Aldinger, F. Synthesis and microstructural characterization of Sr- and Mg-substituted $\mathrm{LaGaO}_{3}$ solid electrolyte. Mater. Chem. Phys., 2007, 102, 240-244.

[33] Huang, K.; Goodenough, J.B. Wet chemical synthesis of Sr- and $\mathrm{Mg}$-doped $\mathrm{LaGaO}_{3}$, a perovskite-type oxide-ion conductor. J. Solid State Chem., 1998, 136, 274-283.

[34] Long, N.J.; Lecarpentier, F.; Tuller, H.L. Structure and electrical properties of Ni-substituted lanthanum gallate perovskites. J. Electroceram., 1999, 399-407.

[35] Trofimenko, N.; Ullmann, H. Transition metal doped lanthanum gallates. Solid State Ionics, 1999, 118, 215-227.

[36] Li, S.; Bergman, B. Doping effect on secondary phases, microstructure and electrical conductivities of $\mathrm{LaGaO}_{3}$ based perovskites. J. Eur. Ceram. Soc., 2009, 29(6), 1139-1146.

[37] Maglia, F.; Anselmi-Tamburini, U.; Chiodelli, G.; Camurlu, H.E.; Dapiaggi, M.; Munir, Z.A. Electrical, structural, and microstructural characterization of nanometric $\mathrm{La}_{0.9} \mathrm{Sr}_{0.1} \mathrm{Ga}_{0.8} \mathrm{Mg}_{0.2} \mathrm{O}_{3-\delta}$ (LSGM) prepared by high-pressure spark plasma sintering. Solid State Ionics, 2009, 180, 36-40.

[38] Huang, K.; Tichy, R.S.; Goodenough, J.B. Superior perovskite oxide-ion conductor; Strontium- and magnesium-doped $\mathrm{LaGaO}_{3}$ : I. Phase relationships and electrical properties. J. Am. Ceram. Soc., 1998, 81, 2565-2575.

[39] Pathak, S.; Steinmetz, D.; Kuebler, J.; Payzant, E.A.; Orlovskaya, N. Mechanical behavior of $\mathrm{La}_{0.8} \mathrm{Sr}_{0.2} \mathrm{Ga}_{0.8} \mathrm{Mg}_{0.2} \mathrm{O}_{3}$ perovskites. Ceram. Int., 2009, 35, 1235-1241.

[40] Ha, S.B.; Choa, Y.H.; Kang, Y.C.; Lee, J.-H. Effect of oxide additives on the sintering behavior and electrical properties of strontium- and magnesium-doped lanthanum gallate. J. Eur. Ceram. Soc., 2010, 30, 2593-2601.

[41] Hsieh, F.-F.; Okinaka, N.; Akiyama, T. Combustion synthesis of doped $\mathrm{LaGaO}_{3}$ perovskite oxide with Fe. J. Alloys Compd., 2009, 484(1-2), 747-752.

[42] Ullmann, H.; Trofimenko, N. Composition, structure and transport properties of perovskite-type oxides. Solid State Ionics, 1999, 119, $1-8$.

[43] Baker, R.T.; Gharbage, B.; Marques, F.M.B. Processing and electrical conductivity of pure, Fe- and Cr-substituted $\mathrm{La}_{0,9} \mathrm{Sr}_{0,1} \mathrm{GaO}_{3}$. J. Eur. Ceram. Soc., 1998, 18, 105-112.

[44] Politova, E.D.; Stefanovich, S.Yu.; Aleksandrovskii, V.V.; Kaleva, G.M.; Mosunov, A.V.; Avetisov, A.K.; Sung, J.S.; Choo, K.Y.; Kim, T.H. The lanthanum gallate-based mixed conducting perovskite ceramics. Phys. Stat. Sol. (c), 2005, 2(1), 196-199.

[45] Politova, E.D.; Aleksandrovskii, V.V.; Kaleva, G.M.; Mosunov, A.V.; Suvorkin S.V.; Zaitsev, S.V.; Sung, J.S.; Choo, K.Y.; Kim,
T.H. Mixed conducting perovskite-like ceramics on the base of lanthanum gallate. Solid State Ionics, 2006, 177, 1779-1783.

[46] Trofimenko, N.; Ullmann, H. Co-doped LSGM: compositionstructure-conductivity relations. Solid State Ionics, 1999, 124, 263 270.

[47] Ishihara, T.; Ishikawa, S.; Hosoi, K.; Nishiguchi, H.; Takita, Y. Oxide ionic and electronic conduction in Ni-doped $\mathrm{LaGaO}_{3}$ based oxide. Solid State Ionics, 2004, 175, 319-322.

[48] Colomer, M.T.; Kilner, J.A. Ni-doped lanthanum gallate perovskites: Synthesis and structural, microstructural, and electrical characterisation. Solid State Ionics, 2010, 182, 76-81.

[49] Ishihara, T.; Akbay, T.; Furutani, H.; Takita, Y. Improved oxide ion conductivity of Co doped $\mathrm{La}_{0.8} \mathrm{Sr}_{0.2} \mathrm{Ga}_{0.8} \mathrm{Mg}_{0.2} \mathrm{O}_{3}$ perovskite type oxide. Solid State Ionics, 1998, 113-115, 585-591.

[50] Ishihara, T.; Ishikawa, S.; Ando, M.; Nishiguchi, H.; Takita, Y. $\mathrm{P}_{\mathrm{O} 2}$ dependence of valence number of $\mathrm{Co}$ in $\mathrm{LaGaO}_{3}$ and its influence on partial electronic and oxide ionic conductivity. Solid State Ionics, 2004, 173, 9-15.

[51] Glowacki, M.; Runka, T.; Domukhovski, V.; Diduszko, R.; Mirkowska, M.; Berkowski, M.; Dabrowski, B. Growth and characterization of perovskite $\mathrm{LaGaO}_{3}$ crystals doped with $\mathrm{Sr}$ and $\mathrm{Mn}, J$. Alloys Compd., 2011, 509, 1756-1759.

[52] Ishihara, T.; Yamada, T.; Arikawa, H.; Nishiguchi, H.; Takita, Y Mixed electronic-oxide ionic conductivity and oxygen permeating property of Fe-, $\mathrm{Co}$ - or Ni-doped $\mathrm{LaGaO}_{3}$ perovskite oxide. Solid State Ionics, 2000, 135, 631-636.

[53] Yashima, M.; Nomura, K.; Kageyama, H.; Miyazaki, Y.; Chitose, N.; Adachi, K. Conduction path and disorder in the fast oxide-ion conductor $\mathrm{La}_{0.8} \mathrm{Sr}_{0.2} \mathrm{Ga}_{0.8} \mathrm{Mg}_{0.15} \mathrm{Co}_{0.05} \mathrm{O}_{2.8}$. Chem. Phys. Lett., 2003, 380, 391-396.

[54] Mori, K.; Onodera, Y.; Kiyanagi, R.; Richardson, J.W.; Itoh, K.; Sugiyama, M.; Kamiyama, T.; Fukunaga, T. Structural and electrochemical properties of $\mathrm{La}_{0.8} \mathrm{Sr}_{0.2} \mathrm{Ga}_{1-x} \mathrm{Fe}_{x} \mathrm{O}_{3}$. Nucl. Instr. Met. Phys. Res. A, 2009, 600, 328-331.

[55] Yaremchenko, A.A.; Shaula, A.L.; Logvinovich, D.I.; Kharton, V.V.; Kovalevsky, A.V.; Naumovich, E.N.; Frade, J.R.; Marques, F.M.B. Oxygen-ionic conductivity of perovskite-type $\mathrm{La}_{1-x} \mathrm{Sr}_{x} \mathrm{Ga}_{1}$ ${ }_{y} \mathrm{Mg}_{y} \mathrm{M}_{0.2} \mathrm{O}_{3-\delta}(\mathrm{M}=\mathrm{Fe}, \mathrm{Co}, \mathrm{Ni})$. Mater. Chem. Phys., 2003, 82, 684690.

[56] Shannon, R.D.; Prewitt, C.T. Effective ionic radii in oxides and fluorides. Acta. Cryst. B, 1969, 25, 925-946.

[57] Chezhina, N.V.; Zolotukhina, N.V.; Bodritskaya, E.V. Magnetic dilution in the $\mathrm{LaCrO}_{3}-\mathrm{LaGaO}_{3}$ system. Rus. J. Gen. Chem., 2005, 75(8), 1233-1236.

[58] Chezhina, N.V.; Piir, I.V.; Zolotukhina, N.V. About nature of electron-ionic conductivity in lanthanum gallates doped with strontium and chromium. Rus. J. Gen. Chem., 2006, 76(10), 1585-1587.

[59] Chezhina, N.V.; Bodritskaya, E.V.; Zhuk, N.A. Magnetic dilution in the $\mathrm{La}(\mathrm{Sr}) \mathrm{NiO}_{3}-\mathrm{LaGaO}_{3}$ system. Rus. J. Gen. Chem., 2008, 78(6), 899-904.

[60] Chezhina, N.V.; Korolev, D.A.; Sukharzhevskii, S.M.; Glumov, O.V. Influence of strontium concentration on interatomic interactions and conductivity in lanthanum gallates doped with strontium and chromium. Rus. J. Gen. Chem., 2010, 80(5), 745-749.

[61] Chezhina, N.V.; Zharikova, E.V.; Sidorova, N.Y. Magnetic dilution in the $\mathrm{La}(\mathrm{Sr}) \mathrm{MnO}_{3}-\mathrm{LaGaO}_{3}$ system. Rus. J. Gen. Chem., 2010, 80(2), 181-196.

[62] Chezhina, N.V.; Zharikova, E.V.; Knyazev, M.N. Magnetic dilution in the $\mathrm{La}(\mathrm{Sr}) \mathrm{CoO}_{3}-\mathrm{LaGaO}_{3}$ system. Rus. J. Gen. Chem., 2010, 80(12), 1937-1942.

[63] Korolev, D.A.; Chezhina, N.V. Influence of strontium concentration on the characteristics of magnetic dilution in the $\mathrm{La}(\mathrm{Sr}) \mathrm{CrO}_{3}-$ $\mathrm{LaGaO}_{3}$ system. Rus. J. Gen. Chem., In Press.

[64] Zvereva, I.; Zueva, L.; Archaimbault, F.; Crespin, M.; Choisnet, J.; Lecomte, J. Crystallochemical, magnetic and electrical properties of the $\mathrm{K}_{2} \mathrm{NiF}_{4}$ type diluted solid solution $\mathrm{Y}_{0.9} \mathrm{Ca}_{1.1} \mathrm{Cr}_{y} \mathrm{Al}_{1-y} \mathrm{O}_{4-\delta}(y \leq$ 0.10): evidence for a partial $\mathrm{Cr}^{3+} \rightarrow \mathrm{Cr}^{4+}$ oxidation. Mater. Chem. Phys., 1997, 48, 103-110.

[65] Brach, B.Ya.; Bobrysheva, N.P.; Reznitskii, L.A.; Chezhina, N.V. About energy of Me-Me interactions at the sesquioxides of titanium and vanadium. Vestnik $L G U, \mathbf{1 9 7 9}, 22,109-112$. (in Russian)

[66] Kalinnikov, V.T.; Rakitin, Yu.V. Introduction to Magnetochemistry. Method of Static Magnetic Susceptibility, Moscow: Nauka, 1980. (in Russian)

[67] Zener, C. Interaction between the $d$-shells in the transition metals. Phys. Rev., 1951, 82(3), 403-405. 
[68] Anderson, P.W.; Hasegawa H. Considerations on double exchange. Phys. Rev., 1955, 100, 675-681.
[69] Barsoukov E., Macdonald J.R. Impedance Spectroscopy. Theory, Experiment, and Application, 2nd ed.; Wiley \& Sons: New Jersey, 2005.

Received: February 25, 2011

Revised: April 12, 2011

Accepted: April 14, 2011

(c) Chezhina and Korolev; Licensee Bentham Open.

This is an open access article licensed under the terms of the Creative Commons Attribution Non-Commercial License (http://creativecommons.org/licenses/by-nc/3.0/) which permits unrestricted, non-commercial use, distribution and reproduction in any medium, provided the work is properly cited. 